Issue 2 (Oktober, 2017)

\title{
PENGARUH KARAKTERISTIK PEKERJAAN DAN KOMPENSASI TERHADAP KEPUASAN KERJA
}

\author{
Abdul Kadir1), Herman Sjaharuddin'2), Suseno H. Purnomo3) \\ abdulkadir199381@gmail.com \\ 1) Mahasiswa Program Studi Manajemen pada Sekolah Tinggi Ilmu Ekonomi Bongaya \\ Makassar \\ 2,3) Dosen Program Studi Manajemen pada Sekolah Tinggi Ilmu Ekonomi Bongaya \\ Makassar
}

\begin{abstract}
ABSTRAK
Penelitian ini bertujuan untuk menguji pengaruh karakteristik pekerjaan terhadap kompensasi dan kepuasan kerja karyawan pada PT. Japfa Comfeed Indonesia, Tbk. Populasi dalam penelitian ini adalah seluruh karyawan yang bekerja pada PT. Japfa Comfeed Indonesia, Tbk. Sebanyak 239 karyawan, sampel dalam penelitian ini sebanyak 70 responden menggunakan simple random sampling. Analisis yang digunakan dalam pengujian hipotesis adalah Structural Equation Modeling (SEM) WarpPLS vers, 5.0. Hasil penelitian ini menunjukkan bahwa secara parsial karakteristik pekerjaan berpengaruh positif dan tidak signifikan terhadap kepuasan kerja dan karakteristik pekerjaan berpengaruh negatif dan signifikan terhadap kompensasi serta kompensasi berpengaruh positif dan signifikan terhadap kepuasan kerja.
\end{abstract}

Kata kunci : Karakteristik Pekerjaan, Kompensasi dan Kepuasan kerja

\section{ABSTRACT}

This study is to determine the influence of Job Characteristic On Compensation and Job Satisfaction of PT. Japfa Comfeed Indonesia, Tbk. The population of this study was all of the employees of PT. japfa Comfeed Indonesia, Tbk. It was 239 employees. The sample of this study was consisted of 70 respondents which was taken by using simple random sampling. The analysis in testing hypothesis used Structural Equation Modeling (SEM) and software WarpPls Version 5.0. The result of this study showed that job characteristic partially had the positive and insignificant influence on satisfaction and Job characteristic had the negative and significant on conpensation and compensation had the positive and significant on job satisfaction with the value 0,949 and significant level 0,01<0,05.

Keywords : Job Characteristic, Compensation and Job Satisfaction

\section{Latar Belakang}

PT. Japfa Comfeed Indonesia Tbk adalah salah satu pelaku usaha agribisnis terbesar di indonesia yang bergerak dibidang produksi pakan ternak, pembibitan ayam, peternakan komersial, produk konsumen, budidaya perairan, peternakan sapi potong serta perdagangan dan lain-lain, dengan kelengkapan ini usaha yang 


\section{JURNAL ORGANISASI DAN MANAJEMEN}

Issue 2 (Oktober, 2017)

dimilikinya, PT. Japfa Comfeed Indonesia Tbk. Merupakan penyedia pangan berbahan protein hewani yang terintegrasi dan terlengkap di tanah air.

Pemeliharaan sumber daya manusia dalam pelaksanaanya menfokuskan pada kepuasan kerja karyawan. Kepuasan kerja yang tinggi memunculkan karyawan yang berprestasi dimana pekerjaan yang menjadi beban kerja karywan dapat diselesaikan dengan baik dan cepat, kesalahan dapat dikurangi, kemungkinan perpindahan karyawan ke lain bagian dapat diperkecil, penggunaan waktu istirahat yang digunakan dengan tepat, yang pada akhirnya meningkatkan efektivitas kerja karyawan.

Berdasarkan teori X dan $\mathrm{Y}$ yang dikemukakan oleh Mc.Gregor dalam Hasibuan (2008:160) bahwa teori pemeliharaan atau teori dua faktor $\mathrm{X}$ dan $\mathrm{Y}$ tentang motivasi, faktor tersebut dinamakan faktor $\mathrm{X}$ yang membuat orang merasa tidak puas dan faktor $\mathrm{Y}$ membuat orang merasa puas (faktor yang memotivasi orang). Kedua faktor tersebut dalam penelitian ini digunakan sebagai teori yang mendasari penciptaan pengaruh antar variabel, yaitu pengaruh karakteristik pekerjaan terhadap kepuasan kerja dan kompensasi terhadap kepuasan kerja. Teori tersebut menjelaskan bahwa tinggi ataupun rendahnya kepuasan kerja individu dipengaruhi oleh karakteristik pekerjaan dan kompensasi.

Kepuasan kerja merupakan evaluasi yang menggambarkan seseorang atas perasaan sikapnya senang atau tidak senang, puas atau tidak puas dalam bekerja (Handoko, 2008:212, dalam Trikardilla, dkk., 2016; Rivai, 2010:856, dalam Anas, 2013). Faktor yang menentukan tinggi ataupun rendahnya tingkat kepuasan kerja (indikator) adalah tingkat upah atau gaji, pekerjaan itu sendiri, rekan kerja,pengawasan dan promosi karier (Luuthans, 2006, dalam Prabowo, 2016).

Teori yang menjelaskan tentang model karakteritik pekerjaan (Job Characteristics) bahwa sebuah pekerjaan yang diperkaya memiliki tingkat dimensi yang tinggi, dan yang pada akhirnya menciptakan tingkat keadaan psikologis kritis yang tinggi dalam diri karyawan. Keadaan psikologis kritis yang tinggi akan menghasilkan kepuasan kerja yang tinggi (Simamora, 2006, dalam Trikardilla, dkk 2016). Faktor yang menentukan tinggi ataupun rendahnya karakteristik pekerjaan (indikator) adalah variasi keterampilan, identifikasi tugas, signifikansi tugas, otonomi, dan umpan balik (Mondy , 2008 dalam Trikardilla, dkk.,2016).

Penelitian mengenai hubungan karakteristik pekerjaan terhadap kepuasan kerja mengacu pada penelitian yang dilakukan Lubis, (2012); Tamalero, dkk,(2012), Ice kemala, (2016); Chandra,dkk, (2014) bahwa karakteristik pekerjaan mempunyai pengaruh positf dan signifikan terhadap kepuasan kerja. Perbedaan hasil penelitian dalam menganalisis pengaruh karakteristik pekerjaan terhadap kepuasan di tunjukan dalam studi Frismandiri (2007); Jaya, (2015) bahwa karakteristik pekerjaan mempunyai pengaruh positif yang tidak signifikan terhadap kepuasan kerja.

Faktor lain yang menentukan kepuasan kerja selain karakteristik pekerjaan adalah kompensasi. Kompensasi adalah semua pendapatan yang berbentuk uang, barang langsung atau tidak langsung yang diterima karyawan sebagai imbalan atas jasa yang diberikan kepada perusahaan (Hasibuan, 2012:118, dalam Nugrahanti, dkk., 2016). Faktor yang mempengaruhi tinggi ataupun rendahnya kompensasi finansial langsung dan tidak langsung (indikator) adalah upah, gaji atau komisi, asuransi kecelakaan dan kesehatan, pemberian jaminan sosial dan imbalan prestasi, sedangkan faktor yang mempengaruhi kompensasi non finasial adalah pekerjaan dan lingkungan kerja (Rivai, 2010:742, dalam Anas, 2013). Bukti penelitian

Halaman 63

Author : Abdul Kadir dkk. (Oktober, 2017). 62 - 75 


\section{JURNAL ORGANISASI DAN MANAJEMEN}

Issue 2 (Oktober, 2017)

terdahulu menjelaskan bahwa kompensasi mempunyai pengaruh yang positf dan signifikan terhadap kepuasan kerja (Rumada, 2008; Dhermawan, dkk., 2012; Prabowo, 2016). Perbedaan hasil penelitian dalam menganalisi pengaruh kompensasi terhadap kepuasan kerja di tunjukan dalam studi Harvey, (2010) bahwa kompensasi mempunyai pengaruh positif dan tidak signifikan terhadap kepuasan kerja.

Fakta lapangan yang diperoleh pada saat dilakukannya pra-penelitian menunjukkan bahwa masih rendahnya tingkat kepuasan kerja karyawan yang disebabkan karena beban kerja karyawan yang sifatnya tidak menentu, hal ini berdampak pada malasnya karyawan dalam bekerja. Fakta lainnya rendahnya motivasi karyawan yang disebabkan dari tingkat pemberian kompensasi yang tidak adil/proporsional, sehingga berdampak terhadap rendahnya tingkat kehadiran karyawan. Selain itu pemanfaatan waktu istrahat oleh karyawan melebihi dari waktu yang di tetapkan oleh perusahaan. Beberapa fakta tersebut menjelaskan bahwa tingkat kepuasan kerja karyawan pada PT. Japfa Comfeed Indonesia, Tbk. masih berada pada kategori yang rendah, , kemudian berdasarkan temuan dari para peneliti terdahulu menunjukkan adanya perbedaan hasil temuan dalam menganalisis kepuasan kerja individu, sehigga berdaskan fakta lapangan dan hasil penelitian terdahulu serta teori $\mathrm{X}$ dan $\mathrm{Y}$ maka penelitian skripsi ini dilakukan dengan judul

\section{TINJUAN PUSTAKA}

\section{Karakteristik Pekerjaan}

Karakteristik pekerjaan adalah pelaksanaan tugas karyawan yang meliputi wewenang, tanggung jawab serta tugas-tugas yang harus dilakukan, dan juga dapat meningkatan kepuasan yang individu peroleh dari karakteristik pekerjaan yang bersangkutan. Karakteristik pekerjaan menyatakan bahwa sebuah pekerjaan yang diperkaya memiliki tingkat dimensi yang tinggi, dan yang pada akhirnya menciptakan tingkat keadaan psikologis kritis yang tinggi dalam diri karyawan. Keadaan psikologis kritis yang tinggi itulah yang akan menghasilkan kepuasan kerja yang tinggi (Gitosudarmo, 2001, dalam Chandra, dkk., 2014; Simamora, 2006, dalam Trikardilla,dkk., 2016).

\section{Kompensasi}

Kompensasi adalah segala sesuatu yang diterima para karyawan sebagai balas jasa untuk kerja mereka (Handoko, 2011:155, dalam Anas, 2013). Pandangan lainnya menjelaskan bahwa Kompensasi merupakan jumlah paket yang ditawarkan organisasi kepada pekerja sebagai imbalan atas penggunaan tenaga kerjanya (Wibowo, 2012:348, dalam Arofah, 2014).

Berdasarkan jenisnya kompensasi dibedakan atas dua yaitu:

\section{a. Kompensasi Finansial}

Yaitu merupakan imbalan yang melibatkan penilaian dan kontribusi pekerjaanya. Adapun jenis-jenis kompensasi finansial (Simamora, 2006:444, dalam Prabowo, 2016) yaitu :

\section{1) Kompensasi finansial langsung}

kompensasi yang sistem pembayarannya dilakukan secara langsung dan diberikan secara langsung kepada karyawan dalam bentuk gaji pokok (base payment). 


\section{JURNAL ORGANISASI DAN MANAJEMEN}

Issue 2 (Oktober, 2017)

\section{2) Kompensasi finansial tidak langsung}

kompensasi yang dibayarkan dalam bentuk uang tetapi sistem pembayarannya dilakukan setelah jatuh tempo, atau pada peristiwaperistiwa yang terjadi di masa akan datang yang telah disepekati sebelumnya. Kompensasi tidak langsung disebut juga dengan tunjangan seperti asuransi, asuransi kesehatan dari perusahaan, tunjangan hari raya (THR) dan dana pensiun.

b. Kompensasi Non Finansial

Kompensasi non finansial terdiri dari kompensasi yang berkaitan dengan pekerjaan itu sendiri seperti tugas yang menarik, tantangan dalam bekerja dan tanggung jawab terhadap pekerjaan dan lingkungan kerja dimana orang itu bekerja seperti seperti lingkungan kerja yang nyaman dan rekan kerja yang mendukung (Martoyo, 2007:120, dalam Prabowo, 2016)

\section{Kepuasan Kerja}

Kepuasan kerja pada dasarnya merupakan sesuatu yang bersifat individual. Setiap individu memiliki tingkat kepuasan yang berbeda-beda seseuai dengan sistem nilai yang berlaku pada dirinya. Semakin tinggi penilaian terhadap kegiatan yang dirasakan sesuai dengan keinginan individu, maka semakin tinggi kepuasan individu terhadap kegiatan tersebut. sehingai secara garis besar kepuasan kerja dapat diartikan sebagai hal yang menyenangkan atau yang tidak menyenangkan yang mana pegawai memandang pekerjaannya (Sahlan, dkk., 2015). Kepuasan kerja adalah sikap emosional yang menyenangkan dan mencintai pekerjaannya (Hasibuan, 2010:202, dalam Nurgrahanti, 2016). kepuasan kerja merupakan hal yang berbeda bagi orang yang berbeda, kepuasan kerja merupakan sikap, suatu keadaan internal, misalnya dikaitkan dengan perasaan prestasi, baik kuantitatif maupun kualitatif (Aziri, 2011, dalam Raditya, 2016). Pandangan lainnya menjelaskan Kepuasan kerja adalah sikap emosional yang menyenangkan dan mencintai pekerjaannya. Sikap ini dicerminkan oleh moral kerja, kedisiplinan dan prestasi kerja (Melayu, 2012:202, dalam Anas, 2013)

\section{METODE PENELITIAN}

Berdasarkan jenisnya, penelitian ini termasuk dalam penelitian penjelasan (explanatory research) dalam penelitian ini peneliti menggunakan penelitian explanatory (penjelasan) bertujuan untuk menguji hubungan antara variabel atau bagaimana suatu variabel mempengaruhi variabel lainnya. Penelitian ini juga termasuk pendekatan penelitian kuantitatif, disebut kuantitatif karena banyak menggunakan angka, mulai dari pengumpulan data, penafsiran terhadap data serta dari penampilan dan hasilnya, demikian juga dengan pemahaman akan kesimpulan penelitian. (Arikunto, 2002 : 9, dalam Sinolla, 2011)

\section{HASIL PENELITIAN}

1. Evaluasi Model Pengukuran (Outer Model) Model 1

Terdapat 3 kreteria dalam analisi evaluasi model yaitu, convergent validity, discriminant validity dan composite reliability. Berikut ini adalah hasil pengolahan data: 
Issue 2 (Oktober, 2017)

\section{a. Convergent Validity (Validitas Konvergen)}

Convergent validity dari model pengukuran dapat dilihat dari korelasi antara skor indikator dengan skor konstruknya (loading factor). suatu model dikatakan baik dan memenuhi pengujian Convergent Validity apabila nilai loading factor dari setiap indikator $\geq 0,70$ dan nilai $p$-value $<0,05$ dianggap signifikan.Dalam buku (Machfud dan Dwi, 2013: 66 dalam Arista, 2015) dijelaskan bahwa dalam beberapa kasus, syarat loading di atas 0.70 sering tidak terpenuhi khususnya untuk kuesioner yang baru dikembangkan. Oleh karena itu, loading antara 0.40-0.70 harus tetap dipertimbangkan untuk dipertahankan. Selanjutnya dijelaskan pula bahwa, indikator dengan loading < 4.50 dihapus dari model. Penghapusan indikator dengan loading antara 0.400.70 dilakukan apabila indikator tersebut dapat meningkatkan AVE dan composite reliability diatas nilai batasannya. Nilai batasan untuk AVE 0,50 dan composite reliability adalah 0,50. Hasil pengolahan Convergent validity dalam pengujian WarPLS Versi 5.0 dapat di jelaskan pada tabel berikut:

Tabel 1. Hasil output Combined loading and cross-loading (model 1)

\begin{tabular}{|c|c|c|c|c|}
\hline Model 1 & KP & KOMP & KK & P value \\
\hline X11 & $(0.447)$ & -0.521 & 0.74 & $<0.001$ \\
\hline X12 & $(0.747)$ & 0.307 & -0.599 & $<0.001$ \\
\hline X13 & $(0.895)$ & -0.414 & 0.48 & $<0.001$ \\
\hline X14 & $(0.755)$ & 0.232 & -0.483 & $<0.001$ \\
\hline X15 & $(0.323)$ & 0.616 & 0.16 & 0.002 \\
\hline Y11 & -0.329 & $(0.325)$ & -0.005 & 0.002 \\
\hline Y12 & -0.035 & $(0.886)$ & 0.681 & $<0.001$ \\
\hline Y13 & 0.162 & $(0.922)$ & 0.113 & $<0.001$ \\
\hline Y14 & -0.022 & $(0.548)$ & -1.288 & $<0.001$ \\
\hline Z11 & 0.252 & 0.256 & $0.878)$ & $<0.001$ \\
\hline Z12 & -0.188 & -0.391 & $0.825)$ & $<0.001$ \\
\hline Z13 & 0.079 & 0.138 & $0.722)$ & $<0.001$ \\
\hline Z14 & -0.139 & 0.125 & $(0.875)$ & $<0.001$ \\
\hline Z15 & -0.001 & -0.139 & $(0.800)$ & $<0.001$ \\
\hline
\end{tabular}

Sumber : data primer (diolah dari WarpPLS Vers 5.0, 2017)

Berdasarkan hasil pengolahan data pada tabel 1 maka dapat di jelaskan sebagai berikut:

a) Convergent validity untuk konstruk karakteristik pekerjaan

Pada model 1 diatas, hasil pengolahan data tersebut menjelaskan bahwa terdapat 2 indikator pada variabel karakteristik pekerjaan yang tidak memenuhi standar Convergent Validity yaitu, X11 dan X15 dengan nilai $<0.70$, sehingga indikator tersebut harus dikeluarkan dari model, sehingga dilakukan pengujian model 2

b) Convergent validity untuk konstruk kompensasi

Hasil pengolahan data pada model 1 diatas menjelaskan bahwa terdapat 1 indikator kompensasi yang tidak memenuhi standar Convergent Validity yaitu Y11 dengan nilai <0.70, sehingga indikator tersebut harus dikeluarkan dari model, untuk indikator Y14 tidak di keluarkan dari model karena merujuk pada pendapat (Sofyan dan Heri, 2011: 18 dalam Hasanuddin, R., \& 


\section{JURNAL ORGANISASI DAN MANAJEMEN}

Issue 2 (Oktober, 2017)

Sjahruddin, H. 2017) nilai standarized loading factor di atas 0,5 dapat diterima, sedangkan di bawah 0,5 dikeluarkan dari model. Sehingga tidak ada alasan yang kuat untuk mengeluarkan indikator tersebut, dan hasil dari dikeluarkanya indikator yang tidak memenuhi standar Convergent validity dapat di jelaskan di model 2.

\section{c) Convergent validity untuk konstruk kepuasan kerja}

Pada model 4.11 dapat disimpulkan bahwa dari 5 indikator kepuasan kerja, yaitu Z11, Z12, Z13, Z14, dan Z15, semua indikator tersebut memenuhi standar Convergent Validity dengan nilai $>0.70$ sehingga indikator-indikator tersebut tidak dikeluarkan pada model 1.

Berdasarkan pengujian pada tabel 1 diatas menunjukkan bahwa masih terdapat indikator yang belum memenuhi pengujian Convergent validity, yaitu indikator karakteristik pekerjaan (X11 dan X15) dan indikator kompensasi (Y11) sehingga dilakukan pengujian model 2, hasil dari pengujian pada model 2 dapat di lihat pada tabel di bawah ini.

Tabel 2. Hasil output Combined loading and cross-loading (model 2)

\begin{tabular}{|c|c|c|c|c|}
\hline model 2 & KP & KOMP & KK & P value \\
\hline X12 & 0.792 & 0.494 & -0.628 & $<0.001$ \\
\hline X13 & 0.866 & -0.286 & 0.535 & $<0.001$ \\
\hline X14 & 0.83 & -0.172 & 0.041 & $<0.001$ \\
\hline Y12 & 0.008 & 0.839 & 0.925 & $<0.001$ \\
\hline Y13 & 0.082 & 0.955 & 0.082 & $<0.001$ \\
\hline Y14 & -0.139 & 0.611 & -1.398 & $<0.001$ \\
\hline Z11 & 0.249 & 0.205 & 0.878 & $<0.001$ \\
\hline Z12 & -0.112 & -0.521 & 0.825 & $<0.001$ \\
\hline Z13 & 0.101 & 0.117 & 0.722 & $<0.001$ \\
\hline Z14 & -0.206 & 0.322 & 0.875 & $<0.001$ \\
\hline Z15 & -0.023 & -0.145 & 0.8 & $<0.001$ \\
\hline
\end{tabular}

Sumber : data primer (diolah dari WarpPLS Vers 5.0, 2017)

Hasil pada Tabel 2 diatas, menunjukkan hasil pengujian Convergent validity untuk model 2, dimana pada model 1 sebelumnya terdapat beberapa indikator pada variabel karakteristik pekerjaan dan kompensasi yang tidak memenuhi standar Convergent validity maka dilakukan pengujian model 2 . Pada pengujian model 2 diatas, semua indikator yang tidak memenuhi standar Convergent validity telah dikeluarkan dari model, sehingga pengujian Convergent validity dalam model 2 telah terpenuhi untuk variabel karakteristik pekerjaan, kompensasi dan kepuasan kerja.

\section{b. Uji Dicriminant Validiti (Validitas Diskriminan)}

Pengujian selanjutnya seletelah Convergent Validity yaitu Dicriminant Validity. suatu konstruk dikatakan baik apabilah telah memenuhi syarat validitas diskriminan yaitu, hasil dalam view combined loading and cross-loadings menunjukkan bahwa loading ke konstruk lain (cross-loading) bernilai lebih rendah daripada loading ke konstruk variabel.Hasil pengujian Dicriminant Validity dapat di lihat pada tabel berikut. 
Issue 2 (Oktober, 2017)

Tabel 3. Hasil Uji Discriminant Validity (model 2)

\begin{tabular}{|c|c|c|c|c|c|l|}
\hline \multirow{2}{*}{ model 2 } & \multirow{2}{*}{ Loading } & \multicolumn{3}{|c|}{ Nilai Loading Ke Konstruk Lain } & \multirow{2}{*}{ Keterangan } \\
\cline { 3 - 6 } & & & KP & KOMP & KK & \\
\hline $\mathrm{X} 12$ & 0.792 & $>$ & & 0.494 & -0.628 & Memenuhi Discriminan validity \\
\hline $\mathrm{X} 13$ & 0.866 & $>$ & & -0.286 & 0.535 & Memenuhi Discriminan validity \\
\hline $\mathrm{X} 14$ & 0.83 & $>$ & & -0.172 & 0.041 & Memenuhi Discriminan validity \\
\hline $\mathrm{Y} 12$ & 0.839 & $>$ & 0.008 & & 0.925 & Memenuhi Discriminan validity \\
\hline $\mathrm{Y} 13$ & 0.955 & $>$ & 0.082 & & 0.082 & Memenuhi Discriminan validity \\
\hline $\mathrm{Y} 14$ & 0.611 & $>$ & -0.139 & & -1.398 & Memenuhi Discriminan validity \\
\hline $\mathrm{Z} 11$ & 0.878 & $>$ & 0.249 & 0.205 & & Memenuhi Discriminan validity \\
\hline $\mathrm{Z} 12$ & 0.825 & $>$ & -0.112 & -0.521 & & Memenuhi Discriminan validity \\
\hline $\mathrm{Z} 13$ & 0.722 & $>$ & 0.101 & 0.117 & & Memenuhi Discriminan validity \\
\hline $\mathrm{Z} 14$ & 0.875 & $>$ & -0.206 & 0.322 & & Memenuhi Discriminan validity \\
\hline $\mathrm{Z} 15$ & 0.80 & $>$ & -0.023 & -0.145 & & Memenuhi Discriminan validity \\
\hline
\end{tabular}

Sumber : data primer (diolah dari WarpPLS 5.0, 2017)

Pada model 2 di tabel 3 telah di jelaskan sebelumya bahwa seluruh indikator pada model tersebut telah memenuhi standar Convergent Validity, sehingga dilanjutkan pada pengujian Dicriminant Validity. pada pengujian Dicriminant validity di model 2, dapat disimpulkan bahwa semua indikator dalam model tersebut telah memenuhi standar dicriminant validity dimana nilai loading ke konstruk lain lebih rendah dibanding nilai loading ke konstruknya sendiri pada kolom yang sama.

\section{c. Uji Composite Reliability}

Pengujian selanjutnya adalah uji reliabilitas konstruk yang dapat diukur dengan 2 kriteria yaitu composite reliability dan cronbach's alpha. Suatu konstruk dinyatakan reliabel jika nilai composite reliability $>0,70$. Penelitian ini menggunakan 3 (tiga) variabel laten yaitu variabel karakteristik pekerjaan $\left(\mathrm{X}_{1}\right)$, kompensasi $\left(\mathrm{X}_{2}\right)$ dan kepuasan kerja (Y) Pengujian composite realibility dalam penelitian dapat dijelaskan pada tabel 4 dibawah ini:

Tabel 4. Hasil Uji Composite Reliability (model 2)

\begin{tabular}{|c|c|c|c|}
\hline MODEL 2 & KP & KOMP & KK \\
\hline R-Squared & & 0.161 & 0.893 \\
\hline Composite reliab. & 0.869 & 0.851 & 0.912 \\
\hline Cronbach's Alpha & 0.773 & 0.729 & 0.878 \\
\hline Avg. Var. Extrac. & 0.688 & 0.663 & 0.676 \\
\hline Full Collin. VIF & 1.051 & 3.843 & 3.941 \\
\hline Q-Squared & & 0.151 & 0.892 \\
\hline
\end{tabular}

Sumber : data primer (diolah dari WarpPLS Vers 5.0, 2017)

Pada tabel 4 di model 2 dapat disimpulkan bahwa variabel karakteristik pekerjaan $\left(\mathrm{X}_{1}\right)$ memiliki nilai Composite reliab $0.869>0.60$, variabel kompensasi $\left(\mathrm{X}_{2}\right)$ memiliki nilai Composite reliab $0.851>0.60$ dan variabel kepuasan kerja $(\mathrm{Y})$ memiliki nilai Composite reliab $0.912>0.60$ sedangkan untuk nilai Cronbach's Alpha dari ke tiga variabel tersebut memiliki nilai $>0.60$. berdasarkan hasil pengujian 


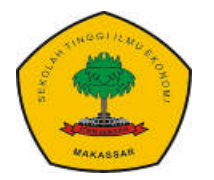

\section{JURNAL ORGANISASI DAN MANAJEMEN}

Issue 2 (Oktober, 2017)

tersebut dapat disimpulkan bahwa semua variabel dalam penelitian ini telah memenuhi standar pengujian Composite reliability.

\section{Evaluasi Model Struktural (Inner Model)}

Tahap selanjutnya dalam penelitian ini adalah evaluasi struktural (inner model) yang meliputi uji kecocokan model (model fit), path coefficient, dan R2. Pada uji kecocokan model terdapat 3 indeks pengujian, yaitu average path coefficient (APC), average $\mathrm{R}$ - squared (ARS) dan average varians faktor (AVIF) dengan kriteria APC dan ARS diterima dengan syarat $\mathrm{p}$ - value $<0,05$ dan AVIF lebih kecil dari 5 (Mahfud Sholihin dan Dwi Ratmono, 2013: 61).

Tabel 5. Hasil Uji Goodness Of Fit

\begin{tabular}{|c|c|c|c|c|}
\hline Goodness of fit & indeks & $p$-value & Kriteria & keterangan \\
\hline Average path coefficient (APC) & 0.422, & $\mathrm{P}<0.001$ & $\mathrm{p}<0.05$ & diterima \\
\hline Average R-squared (ARS) & 0.368, & $\mathrm{P}<0.001$ & $\mathrm{p}<0.05$ & diterima \\
\hline Average adjusted R-squared (AARS) & 0.356, & $\mathrm{P}<0.001$ & $\mathrm{p}<0.05$ & diterima \\
\hline Average block VIF (AVIF) & 1.150 good if $<5$ & & $\mathrm{AVIF}<5$ & diterima \\
\hline Average full collinearity VIF (AFVIF) & 1.528 good if $<5$ & & $\mathrm{AFVIF}<5$ & diterima \\
\hline
\end{tabular}

Sumber : data primer (diolah dari WarpPLS Vers 5.0, 2017)

Pada tabel 5 diatas menjelaskan bahwa APC memiliki nilai sebesar 0.422 dengan nilai $p$-value $<0.001$, sedangkan ARS mempunyai nilai 0.368 dengan nilai p-value $<0.001$, serta nilai AVIF sebesar 1.150. Berdasarkan kreteria APC dan ARS harus memiliki nilai p-value $<0.05$ dan AVIF nya $<5$. maka dari hasil olah data diatas dapat disimpulkan bahwa Inner Model dapat di terima.

a. Hasil Uji Hipotesis

Pengujian hipotesis dalam peneliian ini berdasarkan pada nilai signifikansinya. tingkat singnifikansi dalam penelitian ini yaitu $5 \%$ atau 0.05. Berikut ini hipotesis yang disusun peneliti untuk membuktikan kebenaran dugaan penelitian yang terdiri dari 4 hipotesis yaitu:

$\mathrm{H}_{1} \quad$ : Karakteristik pekerjaan berpengaruh positif dan signifikan terhadap kepuasan kerja karyawan

$\mathrm{H}_{2}$ : Karakteristik pekerjaan berpengaruh positif dan signifikan terhadap kompensasi

$\mathrm{H}_{3} \quad$ : Kompensasi berpengaruh positif dan signifikan terhadap kepuasan kerja karyawan

$\mathrm{H}_{4} \quad$ : Karakteristik pekerjaan melalui kompensasi berpengaruh positif dan signifikan terhadap kepuasan kerja karyawan

Berikut ini tabel hasil penelitian dari effect size yang telah diperoleh berdasarkan pengolahan data: 
Tabel 6. Path coefficients and P-values

\begin{tabular}{|c|c|c|c|c|c|c|c|}
\hline \multicolumn{3}{|c|}{ Path coefficients } & \multicolumn{5}{c|}{ P values } \\
\hline & KP & KOMP & KK & & KP & KOMP & KK \\
\hline KP & & & & KP & & & \\
\hline KOMP & -0.401 & & & KOMP & $<0.001$ & & \\
\hline KK & 0.007 & 0.949 & & KK & 0.477 & $<0.001$ & \\
\hline
\end{tabular}

Sumber : data primer (diolah dari WarpPLS Vers 5.0, 2017)

Berikut ini merupakan gambar hasil dari effect size pengolahan data menggunakan Software Sem- WarPLS Versi 5.0 yaitu:

Gambar 1 Path coefficients and P-values

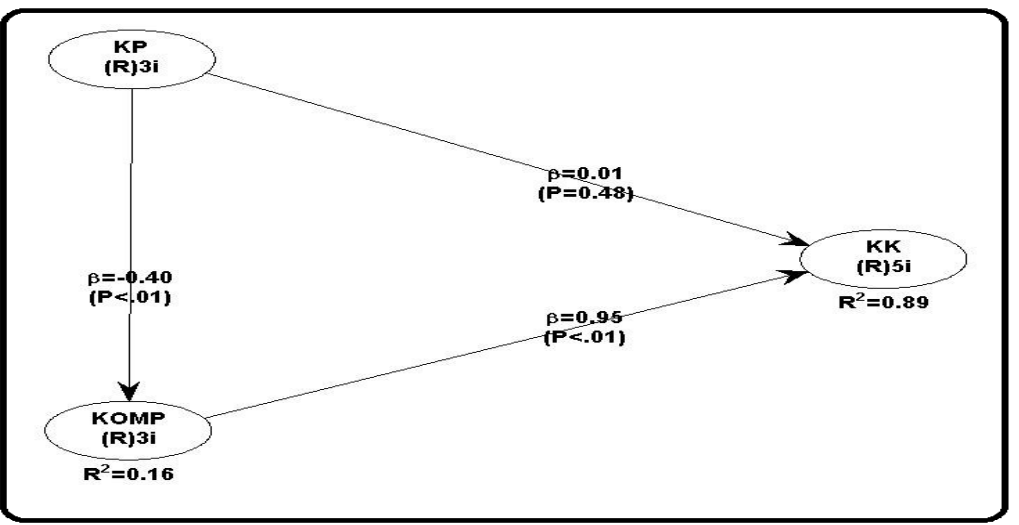

Sumber : Hasil olah data WarPLS Vers, 5. 2017

Angka dalam gambar tersebut merupakan pembulatan dari path coefficients dan $p$ values pada tabel berikut.

$\begin{array}{llll}\text { Keterangan } & : & \text { KP } & : \text { Karakteristik Pekerjaan } \\ & \text { KOMP } & : \text { Kompensasi } \\ & \text { KK } \quad: \text { Kepuasan Kerja }\end{array}$

Dibawah ini hipotesis yang di susun dalam penelitian, akan di jelaskan lebih lanjut :

1) Uji hipotesis 1
a) Hipotesis
$\mathrm{H}_{1} \quad$ : Karakteristik pekerjaan berpengaruh positif dan signifikan terhadap kepuasan kerja karyawan PT. japfa Comfeed Indonesia, Tbk.
b) Dasar pengambilan keputusan $p$-value $<0,05$, maka Hipotesis diterima. $p$-value $>0,05$, maka Hipotesis ditolak.
Pada penelitian ini, Suatu hipotesis dapat diterima atau harus ditolak secara statistik dapat dihitung melalui tingkat signifikansinya yaitu :
c) Keputusan
Berdasarkan hasil pengujian pada tabel 4.14, maka dapat di simpulkan bahwa hipotesis dalam penelitian ini di tolak, terlihat dari nilai $p$-value $0,477>0,05$
d) Kesimpulan 


\section{JURNAL ORGANISASI DAN MANAJEMEN}

Issue 2 (Oktober, 2017)

Berdasarkan hasil pengujian hipotesis diatas, maka dapat disimpulkan bahwa Variabel karakteristik pekerjaan berpengaruh positif dan tidak signifikan terhadap variabel kepuasan kerja pada karyawan PT. Japfa Comfeed Indonesia, Tbk. Hal ini dapat dilihat melalui nilai Koefisien jalur yang yaitu 0,01 dan p-value 0,477>0,05.

2) Uji hipotesis 2

a) Hipotesis

$\mathrm{H}_{2}$ : Karakteristik pekerjaan berpengaruh positif dan signifikan terhadap kompensasi

b) Dasar pengambilan keputusan

Pada penelitian ini, Suatu hipotesis dapat diterima atau harus ditolak secara statistik dapat dihitung melalui tingkat signifikansinyan yaitu: $p$-value $<0,05$, maka Hipotesis diterima.

$p$-value $>0,05$, maka Hipotesis ditolak.

c) Keputusan

Berdasarkan hasil pengujian pada tabel 4.14, maka dapat di simpulkan bahwa hipotesis dalam penelitian ini di sebagian terima, terlihat dari nilai $p$-value $0,001<0,05$

d) Kesimpulan

Berdasarkan hasil pengujian hipotesis diatas, maka dapat disimpulkan bahwa variabel karakteristik pekerjaan berpengaruh negative dan signifikan terhadap variabel kompensasi pada karyawan PT. Japfa Comfeed Indonesia, Tbk. Hal ini dapat dilihat melalui nilai Koefisien jalur yang yaitu $-0,401$ dan $p$-value $0.01<0.05$, berdasarkan hasil tersebut dapat di simpulkan bahwa karakteristik pekerjaan mempunyai pengaruh yang signifikan terhadap kompensasi walaupun pengaruhnya lemah.

\section{3) Uji Hipotesis 3}

a) Hipotesis

$\mathrm{H}_{3}$ : Kompensasi berpengaruh positif dan signifikan terhadap kepuasan kerja karyawan PT. Japfa Comfeed Indonesia, Tbk.

b) Dasar Pengambilan Keputusan

Pada penelitian ini, Suatu hipotesis dapat diterima atau harus ditolak secara statistik dapat dihitung melalui tingkat signifikansinyan yaitu :

$p$-value $<0,05$, maka Hipotesis diterima.

$p$-value $>0,05$, maka Hipotesis ditolak.

c) Keputusan

Berdasarkan hasil pengujian pada tabel 4.14, maka dapat di simpulkan bahwa hipotesis dalam penelitian ini di terima, terlihat dari nilai $p$-value $0,01<0,05$

d) Kesimpulan

Berdasarkan hasil pengujian hipotesis diatas, maka dapat disimpulkan bahwa variabel kompensasi berpengaruh positif dan signifikan terhadap variabel kepuasan kerja pada karyawan PT. Japfa Comfeed Indonesia, Tbk. Hal ini dapat dilihat melalui nilai Koefisien jalur yang yaitu 0,949 dan $p$-value 0,01<0,05, berdasarkan hasil 


\section{JURNAL ORGANISASI DAN MANAJEMEN}

Issue 2 (Oktober, 2017)

tersebut dapat di simpulkan bahwa kempensasi mempunyai pengaruh yang positif dan signifikan terhadap kepuasan kerja, yang artinya semakin tinggi tingkat kompensasi yang di terimah karyawan maka semakin tinggi kepuasan kerja yang dirasakan karyawan.

\section{4) Uji Hipotesis 4}
a) Hipotesis
$\mathrm{H}_{4}$ : Karakteristik pekerjaan melalui kompensasi berpengaruh signifikan terhadap kepuasan kerja karyawan PT. Japfa Comfeed Indonesia, Tbk.
b) Dasar pengambilan keputusan $p$-value $<0,05$, maka Hipotesis diterima. $p$-value $>0,05$, maka Hipotesis ditolak
c) Keputusan
Pada penelitian ini, Suatu hipotesis dapat diterima atau harus ditolak secara statistik dapat dihitung melalui tingkat signifikansinya yaitu :

Gambar 2 Hasil Uji Sobel

\begin{tabular}{|c|c|c|c|c|}
\hline Input: & & Test statistic: & Std. Error: & p-value: \\
\hline a -0.401 & Sobel test: & -3.59997166 & 0.10570889 & 0.00031825 \\
\hline$b 0.949$ & Aroian test: & -3.5862972 & 0.10611195 & 0.00033541 \\
\hline$s_{a} 0.105$ & Goodman test: & -3.61380373 & 0.10530428 & 0.00030174 \\
\hline$s_{b} 0.088$ & Reset all & & Calculate & \\
\hline
\end{tabular}

Sumber: http://quantpsy.org/sobel/sobel.htm (2017)

Nilai standartdized pengaruh karakteristik pekerjaan terhadap Kompetensi (a) sebesar -0,401 dan nilai standar error $\left(S_{a}\right)$ sebesar 0,105, kemudian untuk pengaruh kompensasi terhadap kepuasan kerja dengan nilai standardized (b) sebesar 0,949 dan nilai standar error sebesar $\left(S_{b}\right)$ 0,088. hasil tersebut menyebabkan besaran nilai uji sobel (yang diperoleh melalui Calculation for the Sobel Test) sebesar $-3,599$ pada tingkat signifikan sebesar $0,000<0,05$, sehingga dapat disimpulkan bahwa kompensasi terbukti mampu bertindak selaku variabel pemediasi dalam menjelaskan pengaruh karakteristik pekerjaan terhadap kepuasan. Adapun berdasarkan sifatnya model mediasi tersebut dinyatakan sebagai mediasi sempurna (Complete mediation)

b. Pengujian besaran pengaruh karakteristik pekerjaan (X) dan Kompensasi (Y) terhadap kepuasan kerja (Z) dapat dijelaskan pada tabel berikut:

Tabel 7. Ringkasan Model (Model Summary)

\begin{tabular}{|c|c|c|c|}
\hline Pengukuran & KP & KOMP & KK \\
\hline R-squared & & 0.161 & 0.893 \\
\hline Adj. R-squared & & 0.148 & 0.889 \\
\hline Composite reliab. & 0.869 & 0.851 & 0.912 \\
\hline Cronbach's Alpha & 0.773 & 0.729 & 0.878 \\
\hline Avg. Var. Extrac. & 0.688 & 0.663 & 0.676 \\
\hline
\end{tabular}

Sumber : Hasil olah data WarPLS Vers, 5. 2017 


\section{JURNAL ORGANISASI DAN MANAJEMEN}

Issue 2 (Oktober, 2017)

Berdasarkan hasil pengujian besaran pengaruh variabel karakteristik pekerjaan terhadap kompensasi pada tabel diatas, menjelaskan bahwa nilai $R$-squared variabel karakteristik pekerjaan sebesar 0.161 atau sebesar $16.1 \%$ dan sisanya $83.9 \%$ dipengaruhi oleh variabel lain yang tidak dianalisis dalam penelitian ini seperti tingkat pendidikan, pengalaman kerja dan produktivitas kerja serta variabel lainya.

c. Uji Besaran Pengaruh Variabel Karakteristik Pekerjaan Dan Kompensasi Terhadap Kepuasan Kerja

Berdasarkan hasil pengujian besaran pengaruh variabel karakteristik pekerjaan dan kompensasi terhadap kepuasan kerja karyawan pada tabel 4.15 diatas dengan nilai $R$-squared sebesar 0.893 atau sebesar 89.3\% dan sisanya sebesar $10.7 \%$ di pengaruhi oleh faktor lain yang tidak dianalisis dalam penelitian ini seperi budaya organisasi dan pegembangan karier serta variabel lainya.

\section{KESIMPULAN}

Karakteristik pekerjaan berpengaruh negatif signifikan terhadap kompensasi karyawan. Koefisien jalur bertanda negatif menjelaskan bahwa karakteristik pekerjaan (penguasaan pekerjaan) yang dimiliki karyawan tergolong rendah. Hal ini disebabkan kurangnya kebebasan yang diberikan atasan kepada karyawan didalam mengerjakan pekerjaan yang di bebankan kepada dirinya, pimpinan membatasi ruang gerak karyawan dan karyawan tidak diberikan kebebasan didalam mengembangkan kemampuan yang mereka miliki. Rendahnya kebebasan yang dimiliki karyawan didalam melaksankan tugas-tugas yang dibebankan kepada mereka sementara pada sisi lainya karyawan memiliki kemampuan dalam menyelesaikannya yang dibuktikan dari masa kerja yang dimiliki karyawan yaitu 6 10 tahun. Nilai p-value $0,01<0,05$. Memiliki arti bahwa karakteristik pekerjaan yang dimiliki karyawan terbukti secara nyata mampu memberikan (meningkatkan) pemberian kompensasi pada karyawan PT. Japfa Comfeed Indonesia, Tbk. Hal ini disebabkan karyawan memiliki masa kerja yang cukup lama yaitu 6-10 tahun dan didukung dengan kemampuan perusahaan menyediahkan lingkungan yang nyaman bagi karyawannya di dalam bekerja sehingga mereka terhidar dari rasa jenuh atau bosan didalam mengerjakan pekerjaannya yang dibebankan.

Karakteristik pekerjaan berpengaruh positif tidak signifikan terhadap kepuasan kerja karyawan. Koefisien jalur bertanda positif menjelaskan bahwa karakteristik pekerjaan (penguasaan pekerjaan) yang dimiliki karyawan tergolong tinggi. Hal ini disebabkan tingginya kesadaran karyawan didalam mengerjakan pekerjaan yang dibebankan kepada mereka sehingga pekerjaan tersebut dikerjakan dengan terstruktur sehingga hasilnya mudah dimengerti oleh karyawan lainya. Nilai p-value 0,48 $>0,05$. Memiliki arti bahwa karakteristik pekerjaan yang dimiliki karyawan terbukti secara nyata belum mampu memberikan (meningkatkan) kepuasan kerja pada karyawan PT. Japfa Comfeed Indonesia, Tbk. Hal ini disebabkan karyawan memiliki kesadaran yang tinggi didalam mengerjakan pekerjaan yang dibebankan kepada mereka namun tidak didukung fasilitas yang mendukung bagi karyawan didalam melanjutkan studinya atau pendidikanya,n terlihat dari dominan karyawan yang bekerja pada PT. Jafpa Comfeed Indonesia, Tbk. Berpendidikan SMA/sederajat serta karyawan merasa kurangnya kesempatan yang diberikan perusahaan didalam mengembangkan kemampuan yang mereka dimiliki. 


\section{JURNAL ORGANISASI DAN MANAJEMEN}

Issue 2 (Oktober, 2017)

Kompensasi berpengaruh positif signifikan terhadap kepuasan kerja karyawan. Koefisien jalur bertanda positif menjelaskan bahwa pemberian kompensasi kepada karyawan tergolong tinggi. Hal ini disebabkan kemampuan perusahaan didalam menjamin kesalamatan kerja karyawanya serta karyawan tidak khawatir dengan masa pensiun mereka karena perusahaan telah menjamin masa pensiun tersebut. Nilai p-value $0,01<0,05$. Memiliki arti bahwa kompensasi yang diberikan pihak perusahaan kepada karyawan terbukti secara nyata mampu memberikan (meningkatkan) kepuasan kerja pada karyawan PT. Japfa Comfeed Indonesia, Tbk. Hal ini disebabkan kemampuan perusahaan didalam menjamin kesalamatan kerja karyawanya yang didukung kemampuan perusahaan memberikan suasana yang nyaman bagi karyawan didalam bekerja sehingga karyawan mampu bekerja dengan maksimal.

Studi ini merekomendasikan kepada peneliti lanjutan untuk dilakukan pada profesi yang berbeda. Dalam upaya meningkatkan karakteristik pekerjaan karyawan, pihak manajemen diharapkan memberikan tanggung jawab kepada karyawannya untuk menyelesaikan pekerjaan sesuai dengan keinginan mereka dan tidak menyimpan dari prosedur kerja perusahaan sehingga akan membuat karyawan merasa nyaman didalam menyelesaikan setiap tugas - tugas yang dibebankan kepada mereka. Dalam upaya mempertahankan pemberian kompensasi yang diberikan pihak manajemen, karyawan hendaknya mempertahankan hasil kerja yang telah dicapai sebagai bahan pertimbangan dalam pengambilan keputusan dimasa yang akan datang. Dalam upaya meningkatkan kepuasan kerja karyawan, pihak manajemen diharapkan. Pihak manajemen hendaknya menepatkan karyawan berdasarkan minat dan kemampuan yang dimiliki karyawan pada bidan yang mereka gemari.

\section{DAFTAR PUSTAKA}

Anas, K. (2013). Pengaruh Kompensasi dan Lingkungan Kerja Terhadap Kepuasan Kerja Karyawan PT. Karya Mitra Muda. Jurnal Manajemen, 2(01).

Arofah, S., Fathoni, A., \& Minarsih, M. M. (2015). Pengaruh Kompensasi, Keahlian dan Lingkungan Kerja terhadap Kepuasan Kerja Karyawan pada Bank Permata Cabang Bangkong Semarang. Journal of Management, 1(1).

Chandra, L., Mulyanto, J. C., Nugroho, A.,(2014). analisa pengaruh karakteristik pekerjaan terhadap kepuasan dan kinerja karyawan di hotel d'season surabaya

Dhermawan, dkk (2012). Pengaruh Motivasi, Lingkungan Kerja, Kompetensi, Dan Kompensasi Terhadap Kepuasan Kerja Dan Kinerja Pegawai Di Lingkungan Kantor Dinas Pekerjaan Umum Provinsi Bali. Jurnal Manajemen, Strategi Bisnis, Dan Kewirausahaan, 6(2), 173-184.

Frismandiri, D. (2007). Analisis Pengaruh Karakteristik Pekerjaan, Kepuasan Kerja, Dan Komitmen Terhadap Kinerja Karyawan. Jurnal Ekonomi MODERNISASI, $3(2), 114-134$

Harvey Hiariey. (2010). pengaruh kompensasi dan karakteristik pekerjaan terhadap kepuasan kerja karyawan unit produksi pt. sarindah bakery ambon

Hadianto, B., Fakultas, D., Jurusan, E., Maranatha, A. K., Prof, J., Suria, D., \& No, S. (2009). Pengaruh Profitabilitas dan Kesempatan Investasi terhadap Kebijakan Dividen : Studi Empirik pada Emiten Pembentuk Indeks LQ45 di Bursa Efek Indonesia, 1(1), 70-84. 


\section{JURNAL ORGANISASI DAN MANAJEMEN}

Issue 2 (Oktober, 2017)

Hasibuan, Melayu. (2008). Manajemen Sumber Daya Manusia, edisi revisi. Jakarta :Bumi Aksara

Ice Kemala. (2016). karakteristik individu, karakteristik pekerjaan dan karakteristik organisasi pengaruhnya terhadap kepuasan kerja pegawai .

Kuncoro, A. E. Riduwan. 2011. Cara Menggtinakan Dan Memaknai Path Analysis (Analisis Jalur). Bandung: Alfabeta.

Lubis, Y. (2012). Pengaruh Karakteristik Individu, Karakteristik Pekerjaan, Iklim Organisasi terhadap Kepuasan dan Kinerja Karyawan, 11(2), 212-228

Lena Ellitan. (2002). Praktik-Praktik Pengelolaan Sumber Daya Manusia Dan Keunggulan Kompetitif Berkelanjutan. Jurnal Manajemen Dan Kewirausahaan, 4, pp.65-76.

Nugrahanti, P., Sunuharyo, B. S., \& Utami, H. N. (2016). pengaruh kompensasi finansial dan non finansial terhadap kepuasan kerja dan prestasi kerja karyawan (Studi pada karyawan PT Telkom Indonesia Witel Jatim Selatan Malang). Jurnal Administrasi Bisnis, 40(1)

Ovi engga Arista, O. (2015). Pengaruh Persepsi Atas Corporate Social Responsbility Terhadap Kepuasan Kerja Dan Komitmen Organisasi (Survey Pada Hotel Bintang V Di Yogyakarta) (Doctoral dissertation, Fakultas Ekonomi).

Raditya, K., \& Indrawati, A. D. (2016). pengaruh lingkungan kerja fisik dan kompensasi finansial terhadap kepuasan kerja bagian tukang jahit yara garment. e-jurnal manajemen universitas udayana, 5(3)

Rivai, Veithzal. 2010. Manajemen Sumber Daya Manusia untuk Perusahaan. Jakarta: Raja Grafindo Persada.

Sahlan, N. I., Mekel, P. A., \& Trang, I. (2015). Pengaruh Lingkungan Kerja, Kepuasan Kerja Dan Kompensasi Terhadap Kinerja Karyawan Pada PT. Bank Sulut Cabang Airmadidi. Jurnal Riset Ekonomi, Manajemen, Bisnis dan Akuntansi, 3(1).

Sinollah (2011). Pengaruh Kompensasi Terhadap Kepuasan Kerja Karyawan (Studi Pada PT . PLN (Persero) Distribusi Jawa Timur. (2016), (August 2014), 0-14.

Tri Kardilla, Herman Sjahruddin, Heslina. (2016). Dampak Karakteristik Pekerjaan dan Individu Pada Kepuasan Kerja Karyawan. 